ORIGINAL RESEARCH ARTICLE

\title{
Determinants of Home Delivery among Women attending Antenatal Care in Bagwai Town, Kano Nigeria
}

\author{
DOI: $10.29063 / a j r h 2017 / v 21 \mathrm{i} 4.8$
}

\author{
Salisu Abubakar *, Dalhatu Adamul Ruqayya Hamzal and Jamila B. Galadima ${ }^{1}$ \\ Department of Nursing Science, Bayero University Kano, Nigeria ${ }^{l}$
}

*For Correspondence: Email: sabubakar01@gmail.com

\begin{abstract}
Unskilled home delivery is a threat to maternal and child health. In northern Nigeria, many pregnant women attend antenatal care but opt to deliver at home despite knowing the potential consequences. An institutional delivery, helps reduce various complications during childbirth, and therefore decreases the rates of maternal and child mortality. To explore the determinants of home delivery after attending antenatal services, this study employed a cross-sectional design and a non-probability purposive sampling technique. Findings of the study revealed that, majority $(74.1 \%)$ of the women predominantly between the ages of $25-$ 35 years, $(29 \pm 6.4)$ quit antenatal care to deliver at home mainly due to maternity staff attitude and presence of male healthcare workers during delivery. The study concluded that, pregnant women are aware of the importance of antenatal care and, do deliver at home due to behavioural, sociocultural and religious preferences. To combat the maternal mortality in this region, values and beliefs of the women and families should be put into cognizance. Additionally, healthcare workers should be respectful and create a conducive environment in the maternity centres. More maternity centres including waiting homes should be provided. (Afr J Reprod Health 2017; 21[4]: 73-79).
\end{abstract}

Keywords: Pregnancy, unskilled delivery, maternal, antenatal and child health

\section{Résumé}

L'accouchement à domicile non qualifiée est une menace pour la santé maternelle et infantile. Dans le nord du Nigéria, de nombreuses femmes enceintes bénéficient de soins prénatals, mais choisissent d'accoucher à domicile malgré les conséquences potentielles. Un accouchement en établissement contribue à réduire les diverses complications lors de l'accouchement et diminue donc les taux de mortalité maternelle et infantile. Pour explorer les déterminants de l'accouchement à domicile après avoir assisté à des services prénatals, cette étude a utilisé une conception transversale et une technique d'échantillonnage raisonnée non probabiliste. Les résultats de l'étude ont révélé que la majorité $(74,1 \%)$ des femmes âgées entre 25 et 35 ans $(29 \pm 6,4)$ abandonnent les soins prénatals pour accoucher à domicile principalement en raison de l'attitude du personnel de maternité et d'accouchement. L'étude a conclu que les femmes enceintes sont conscientes de l'importance des soins prénataux et qu'elles accouchent à domicile en raison de leurs préférences comportementales, socioculturelles et religieuses. Pour combattre la mortalité maternelle dans cette région, les valeurs et les croyances des femmes et des familles devraient être mises en évidence. En outre, les travailleurs de la santé doivent être respectueux et créer un environnement propice dans les centres de maternité. Il faut prévoir encore plus des centres de maternité, y compris les centres d'attente. (Afr J Reprod Health 2017; 21 [4]: 73-79).

Mots-clés: Grossesse, accouchement non qualifié, santé maternelle, prénatale et infantile

\section{Introduction}

Antenatal care is a form of health service provided to a woman throughout pregnancy to ensure a safe gestation and childbirth, and prevent complications to the mother and the baby ${ }^{1}$. This type of care offers a range of healthcare services including prevention, detection, and treatment of anaemia, malaria, malnutrition, pre-eclampsia, sexually transmitted infections (STIs), and prevention of mother to child transmission of human immunodeficiency virus (HIV).

Sufficient antenatal care (ANC) and skilled obstetric help during delivery are essential strategies that considerably decreases maternal mortality and morbidity rate ${ }^{2}$. The World Health Organization $^{3}$ endorses four antenatal visits, with different and tailored care during each visit. 
Nevertheless, women with potential complications, special needs, or conditions beyond the scope of basic care may require additional visits. Antenatal care plays significant roles in improving the health status of both the expecting mother and the child.

The World Health Organization ${ }^{4}$ estimates that 830 women across the world die each day as a result of pregnancy and childbirth related complications and the greater proportion of these deaths occur in sub-Saharan Africa. ANC offers the opportunity to provide pregnant women with information to treat existing social and medical conditions and screen for other risk factors. However, it is not adequate to receive ANC alone, since most of the fatal complications occur during or immediately after delivery ${ }^{5}$. Consequently, skilled institutional delivery is essential in prevention, early detection, and management of obstetric complications.

Despite the global outcry to address the problem of maternal mortality, unskilled delivery remains an issue in many African countries. In northern Nigeria, cultural beliefs relating to childbirth negatively affects the campaign to combat maternal mortality ${ }^{6}$. A survey of 6,882 Nigerian women established that $26 \%$ had received antenatal care and only $13 \%$ delivered at institution with skilled birth attendants while $86 \%$ gave birth at home under unskilled care ${ }^{7}$. A similar study involving 124 northern Nigerian women reported that over $70 \%$ of the respondents confirmed culture as a major obstacle to institutional delivery ${ }^{8}$.

Unskilled home delivery is associated with greater chances of obstetric complications including maternal and child mortality. A systematic review of literature encompassing 500,000 planned homebirths in low-risk women reported that perinatal mortality rates for home deliveries tripled that of hospital delivery ${ }^{9}$. Consequently, it can be reasoned that skilled institutional delivery is healthier and safer for the mother and child. One reason could be the fact that healthcare facilities provide appropriate attention and hygienic environment during delivery and reduce the risk of complications and infection ${ }^{10}$.

In 2015, maternal mortality ratio (MMR) in Nigeria was 814 per 100,000 live births, the highest rate in Africa and twice the rate in most other developing countries ${ }^{11}$. This rate was disquieting. Nevertheless, the mortality varies by geopolitical zone and urban or rural settings. MMR is higher in northern Nigeria particularly north-eastern geopolitical zone which was earlier estimated at 1,749 per 100,000 live births ${ }^{12}$. Although, subsequent findings of a study conducted in four northern states (mainly northwestern) put the rate at 1,271 per 100,000 live births $^{13}$. Similarly, an analysis of maternal death in Kano alone reported a rate of 1,625 per 100,000 live births ${ }^{14}$.

Nevertheless, many women have different reasons why they prefer home delivery, as such the need to explore factors that influence women's delivery at home after attending antenatal care formed the basis of the study.

\section{Methods}

The study was conducted in the antenatal clinic of Abbas Basic Health Center, Bagwai. A local healthcare facility in North-western state of Kano, Nigeria. The healthcare facility has fifty (50) bed capacity and was established 1991. It serves an estimated catchment population of about 162,847 people.

Study participants comprised pregnant women who had at least delivered once and are receiving antenatal care at Abbas Basic Health Centre during the period of study. A cross sectional, non-probability purposive sampling was used to recruit 139 pregnant women who attended the antenatal unit during the study period. Sample size was statistically determined based on established estimate of home delivery ${ }^{15}$. The initial sample size was 132 but 5\% was added to allow for incomplete and non-response.

To explore factors behind women's choice for unskilled home delivery despite attending antenatal care, a structured questionnaire was used. The research instrument was evaluated for reliability and validity using Cronbach's Alpha. Data was collected using interviewer administered questionnaire and was interpreted to those participants who cannot understand English language. Obtained data was entered into an Excel sheet 2013 and subsequently analysed using SPSS 
Table 1: Socio-demographic Characteristics of the Respondents

\begin{tabular}{|c|c|c|}
\hline Variable $N=139$ & Frequency & Percent \\
\hline \multicolumn{3}{|l|}{ Age } \\
\hline $17-24$ & 39 & 28.1 \\
\hline $25-35$ & 79 & 56.8 \\
\hline$>35$ & 21 & 15.1 \\
\hline Total & 139 & 100 \\
\hline \multicolumn{3}{|l|}{ Tribe } \\
\hline Hausa & 96 & 69.1 \\
\hline Fulani & 43 & 30.9 \\
\hline Total & 139 & 100 \\
\hline $\begin{array}{l}\text { Educational level } \\
\text { Arabic school }\end{array}$ & 58 & 41.7 \\
\hline Primary school & 54 & 38.8 \\
\hline Secondary school & 21 & 15.1 \\
\hline Tertiary level & 6 & 4.3 \\
\hline Total & 139 & 100 \\
\hline \multicolumn{3}{|c|}{ Husbands' occupation } \\
\hline Civil servant & 40 & 28.8 \\
\hline Petty trader & 58 & 41.7 \\
\hline Unskilled manual & 41 & 29.5 \\
\hline Total & 139 & 100 \\
\hline \multicolumn{3}{|l|}{$\begin{array}{l}\text { Respondents } \\
\text { occupation }\end{array}$} \\
\hline House wives & 126 & 90.6 \\
\hline Civil servant & 13 & 9.4 \\
\hline Total & 139 & 100 \\
\hline
\end{tabular}

Table: 2: ANC Attendance and Neonatal Death during Delivery

\begin{tabular}{lllll}
\hline & \multicolumn{3}{l}{ Neonatal death } & \multicolumn{2}{l}{$\begin{array}{l}\text { Lost } \\
\text { more }\end{array}$} \\
ANC Attendance & Never & Lost one & than one & Total \\
\hline Always & 16 & 61 & 6 & 83 \\
When sick & 3 & 12 & 29 & 44 \\
$\begin{array}{l}\text { Sick - First } \\
\text { Attending }\end{array}$ & 0 & 0 & 12 & 12 \\
Total & 19 & 73 & 47 & 139 \\
\hline
\end{tabular}

version 23.0. Ethical approval to conduct the study was sought and granted by the local health authority.

\section{Results}

Out of the 139 respondents, $79(56.8 \%)$ were between the ages of 25-35 years, 39 (28.1\%) between 17-24years and only $21(15.1 \%)$ were above the age of 35years. Mean age of the respondents was $29 \pm 6.4$. Fifty-eight (58) (41.7\%) of the study participants attended non-formal Arabic school as their highest level of education followed by 54 (38.8\%) who acquired both Arabic and primary education. While 21 (15.1\%) possessed secondary school as their highest qualification, only $6(4.3 \%)$ achieved tertiary education level. In addition, 126 (90.6\%) of the study participants were full house wives and only $13(9.4 \%)$ were civil servants. On the other hand, majority $(41.7 \%)$ of the participant's husbands were petty traders while $29.5 \%$ and $28.8 \%$ were unskilled labourers and civil servants respectively. Overall study participants were Muslims and Hausa/Fulani (Table: 1).

Majority $(59.7 \%)$ of the participants were aware of the importance of ANC and attended antenatal clinic whenever they were pregnant. However, the remaining proportion (40.3\%) mainly those without formal primary education, disclosed that they attended the clinic only when sick or noticed an abnormality and $21.6 \%$ of this group were attending the clinic for first time. A chi-square statistical analysis showed significant association between level of education and ANC attendance $\mathrm{p}<0.01$ (2-tailed).

Result also showed that majority of the participants 97 (69.8\%) had delivered between 1-5 times while $42(30.2 \%)$ had the experience of childbirth more than 5 times. Only 19(13.7\%) of the respondents had never lost a child during delivery, whereas $73(52.5 \%)$ and $47(33.8 \%)$ had lost one and more than one child during childbirth respectively (Table: 2 ). When association between neonatal deaths during delivery and ANC attendance was tested, findings showed a strong relationship between the two variables at an $r$ value of 0.610 and $p$ value $<0.0001$.

On the respondents view regarding place of delivery, majority (73.4\%) preferred home delivery, only $26.6 \%$ indicated willingness for hospital delivery (Figure: 1). More so, using bivariate analysis, willingness for home delivery was found to be associated with age and parity of the study respondents. Correlation was significant at $\mathrm{p}<0.01$ level (2-tailed). Furthermore, $48.2 \%$ preferred to be attended by female midwives 


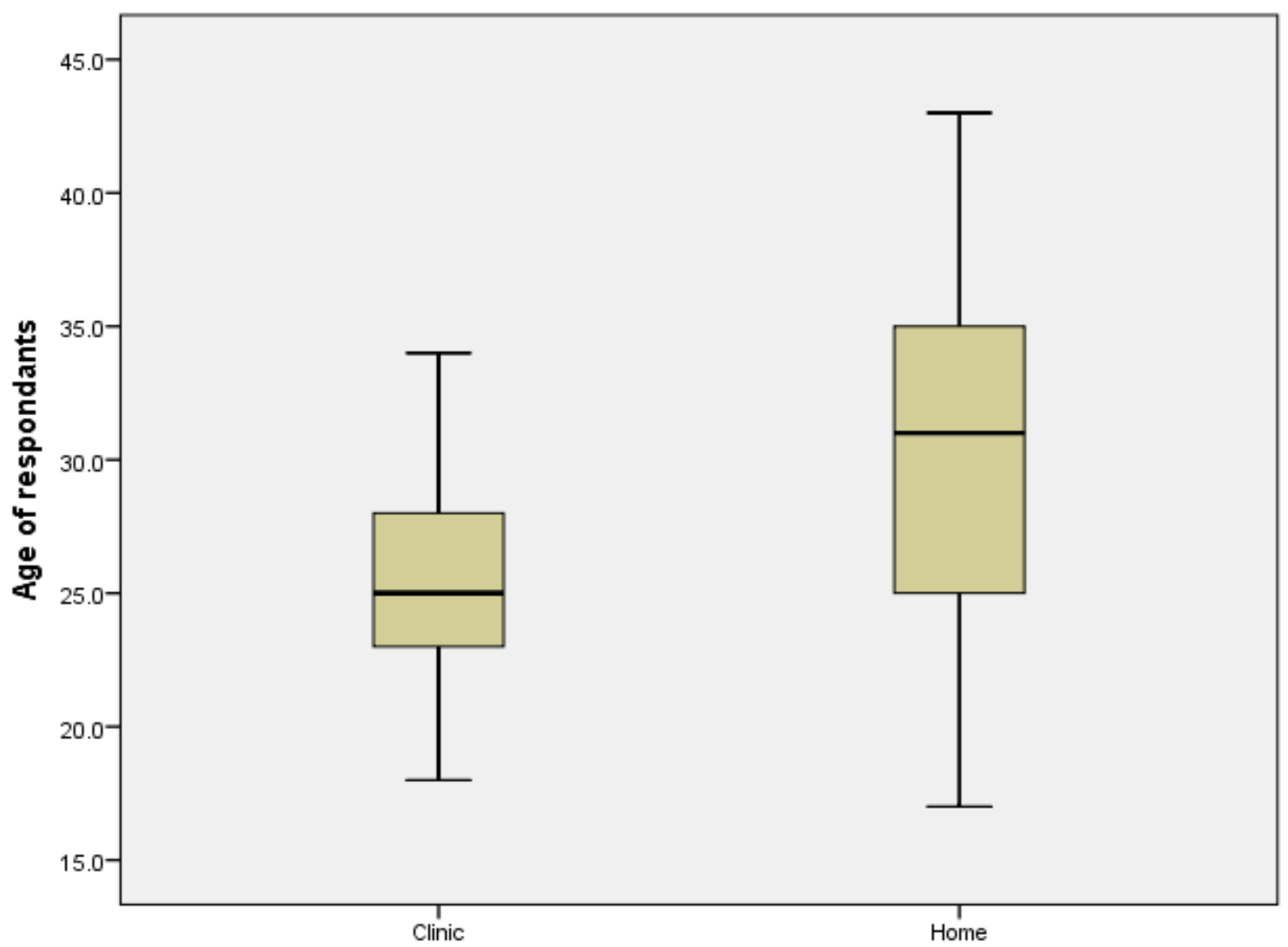

Figure: 1. Participants' Preferred Place of Delivery

Just like home delivery

Feel safer at home

Customs

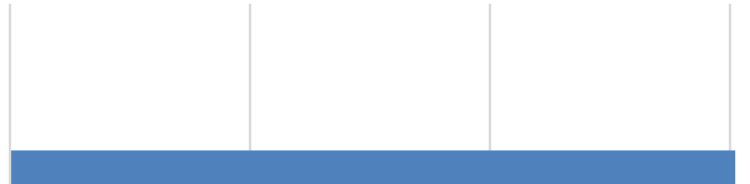

Male attendance

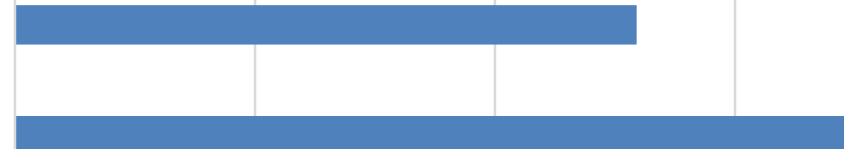

Staff attitude

Figure 2: Factors Determining Home Delivery 
during childbirth, $36.7 \%$ by traditional birth attendants (TBA) and $15.1 \%$ felt more comfortable when attended by family members. Of the $73.4 \%$ that preferred home delivery, $20.14 \%$ disliked hospital delivery because of staff attitude, $17.27 \%$ due to male attendance, $12.95 \%$ due to custom, $7.9 \%$ felt safer at home, while a small proportion (15.11\%) indicated no reason (Figure 2).

Findings of the study further revealed that only a little over one quarter $(25.9 \%)$ of the respondents had full antenatal care and the benefit of institutional delivery while majority (74.1\%) opted out the process of ANC and delivered at home. Of the $74.1 \%$ that quit the process of care and delivered under the hands of unskilled personnel, $37.4 \%$ did so due to family issues and $13.7 \%$ due to attitude of workers. While $12.2 \%$ quite due to long distance to the health facility, 10.9\% abandoned ANC including skilled delivery due to financial difficulties.

\section{Discussion}

This study uncovers the high alarming rate of unskilled home delivery among women who received antenatal services in rural northern Nigeria. This is despite efforts to reduce maternal and child mortality through promotion of skilled attendance at childbirth ${ }^{16}$. Irrespective of the fact that high parity is associated with maternal dangers ${ }^{17}$, the study found that rural women with five (5) children and above were the least (30.2\%) in the utilization of healthcare services during pregnancy and childbirth. According Olusegun, Thomas and Michael ${ }^{18}$, education plays a key role in promoting healthy pregnancy, childbirth and post-natal care. In this study, majority of the respondents $(80.5 \%)$ attained only primary education and below which could be another reason why they did not understand the importance of skilled birth attendance. Although, few of the current study respondents stated finances as a barrier to skilled birth attendance, $90.6 \%$ of the women did not have a reliable source of income. Likewise, respondent's partners were mainly petty traders (41.7\%) and unskilled labourers (29.5\%), suggesting that hospital delivery finances may be an obstacle to access and utilization of healthcare services during child birth. This is similar to the finding of another study conducted in Indonesia ${ }^{10}$ although, availability and accessibility to community midwives was a major difference between the two studies.

The current study excluded women with no prior experience of pregnancy or childbirth, findings reveals that majority (69.8\%) of the antenatal clinic attendees are well experienced in terms of pregnancy and childbirth. Thus, findings confirmed that parity and age significantly plays an important role in seeking care during pregnancy. An array of studies ${ }^{16-18}$ reveal that, increased parity decreases utilization of health services during pregnancy and leads to higher chances of home delivery. Findings of the current study reaffirmed this and the practice is associated with increased chances of neonatal death at birth. The increase in likelihoods of home delivery of this group may be due to the fact that, multiparous women believe they are better experienced and have developed some level of skills and confidence in childbirth.

Additionally, findings from this study showed that many $(59.7 \%)$ pregnant women regularly attended antenatal care during their pregnancies. On the other hand, it was alarming to discover that over $40 \%$ of the women were not aware of the importance antenatal care and sought healthcare only when they fell sick. This was in accordance with the findings of Abebe et $\mathrm{al}^{19}$. More so, it was also disturbing that despite the high ANC attendance, majority of the respondents preferred to deliver at home than in a healthcare institution. Accordingly, 51.8\% of those with high ANC attendance ended up on the hands of nonskilled birth attendants. However, $48.2 \%$ of those who delivered at home despite ANC preferred to be attended by skilled birth attendants. This suggests that the groups accept skilled delivery but non-institutional due to delivery factors like attitude of healthcare workers or male attendance during childbirth.

Because the study was limited to responses of some pregnant women at the ANC clinic, partners and family members were not 
involved to further explore certain factors that hinder the pregnant women from institutional skilled delivery. These factors are highlighted in the result section. Nevertheless, it is common knowledge that northern Nigerians (particularly the Muslim population) prefer not to have male attendants during labour and childbirth. This affirmed the findings by Okeshola and Sadiq ${ }^{8}$ which revealed that majority of women in Southern Kaduna do not accept hospital services during pregnancy and child birth and believed that their privacy is violated when male healthcare workers are present.

Conclusively, this study revealed that, majority of women in a sub-urban community of Kano, northern Nigeria were aware of the importance ANC to their health and their potential child. However, sociocultural and religious factors regulated their choice of care and delivery. Precise factors such as male attendance during delivery, family beliefs, distance to maternity clinics and financial constrains determined their choice of delivery place. Attitude of healthcare workers towards the expectant mother was another important factor. To effectively combat the problem of maternal and child mortality in northern Nigeria, communities and women groups need to be more involved in designing the maternal healthcare. While doing this, values and beliefs of women and families should be appreciated. Additionally, more skilled personnel, community midwives and maternity centres should be provided particularly at sub-urban and rural communities. Besides, behavioural change of healthcare workers to follow the international standards of respectful maternity should be advocated at all levels.

\section{Contribution of Authors}

Abubakar, S conceived the idea, designed the study protocol together with Dalhatu, A. Hamza, R and Galadima, JB secured ethical clearance and collected the data. Abubakar, S analysed the data and prepared the manuscript. All authors mentioned in the article approved the manuscript.

\section{References}

1. Berhan, $\mathrm{Y} \&$ Berhan, A. Antenatal care as means of increasing birth in the health facility and reducing maternal mortality: A systematic review. Ethiopian Journal of Health Sciences 2014; 24(0): 93-104.

2. World Health Organization. WHO Antenatal Care Randomised Trial: Manual for the Implementation of the New Model. 2002; http://apps.who.int/iris/bitstream/10665/42513/1/W HO_RHR_01.30.pdf accessed 13/01/2016

3. World Health Organization. World Health Report. Geneva: Statistical Annex, WHO; 2002.

4. World Health Organization. Global Health Observatory Data: Maternal Mortality 2015; www.who.int/gho/maternal_health/mortality/matern al_mortality_text/en/

5. Ewa, E E, Lasisi, CJ, Maduka, SO, Ita, AE, Ibor, UW \& Anjorin, OA. Perceived factors influencing the choice of antenatal care and delivery centres among childbearing women in Ibadan north south-western, Nigeria. Ethiopian Journal of Environmental Studies and Management EJESM 2012; 5(4).

6. Wall, LL. Dead Mothers and Injured Wives: The Social Context of Maternal Morbidity and Mortality among Hausa of Northern Nigeria. Studies in Family Planning 1998; 29: 341 - 359.

7. Henry, VD \& Dahiru, T. Utilization of Non-Skilled Birth Attendants in Northern Nigeria: A Rough Terrain to the Health-Related MDGs. African Journal of Reproductive Health, 2010; 14(2): 37

8. Okeshola, F \& Sadiq, IT. Determinants of Home Delivery among Hausa in Kaduna South Local Government Area of Kaduna State, Nigeria. American International Journal of Contemporary Research 2013; 3(5): 78 - 85

9. Crespingy, L \& Salvescu, J. Homebirth and the future child. J Med Ethics 2014; 40 (12): 807-812

10. Titaley, CR, Hunter, CL, Dibley, MJ \& Heywood, P. Why do women still prefer TBA and at home delivery: a qualitative study on delivery care services in West Java Province, Indonesia. BMC Pregnancy Childbirth 2010; 10: 43

11. WHO, UNICEF, UNFPA, World Bank Group, and United Nations Population Division Maternal Mortality in $1990 \quad$ - 2015. 2015. http://www.who.int/gho/maternal_health/countries/ nga.pdf accessed on 13/01/2016

12. National Population Commission (NPC) Nigeria and ORC Macro. Nigeria Demographic and Health Survey. Calverton, Maryland: National Population Commission and ORC Macro 2008.

13. Doctor, H, Findley, S \& Afenyadu, G. Estimating Maternal Mortality Level in Rural Northern Nigeria by the Sisterhood Method. International Journal of Population Research article ID 464657, 2012; 5

14. Ibrahim, YAR'ZEBER. Temporal Analysis of Maternal Mortality in Kano State, Northern Nigeria: A SixYear Review. American Journal of Public Health Research, 2014; 2 (2): 62-67

15. Nduka, I \& Nduka, EC. Determinants of noninstitutional deliveries in an urban community in Nigeria. J Med Investig Pract 2014; 9:102-107. 
16. Envuladu, EA Agbo, HA Lassa, S Kigbu, JH \& Zoakah, AI. Factors determining the choice of a place of delivery among pregnant women in Russia village of Jos North, Nigeria: achieving the MDGs 4 and 5 Int J Med Biomed Res 2013; 2(1):23-27

17. Adetoro, OO. Maternal Mortality: The Way Forward. 2013.

http://www.who.int/pmnch/activities/countries/niger iapresentation.pdf accessed on 13/01/2016

18. Ogunjimi L Olusegun, OL, Thomas, IR \& Michael, IR. Curbing Maternal and Child Mortality: The Nigerian experience. International Journal of Nursing and Midwifery 2012; 4(3): 33 - 39.

19. Abebe, F, Berhane, Y \& Girma, B. Factors associated with home delivery in Bahirdar, Ethiopia: A case control study. BMC Research Notes. 2012; 5:653. 